\title{
Activity Profiles by Position in Youth Elite Soccer Players in Official Matches
}

(ㄷ)(1) (요 $\Theta$

\author{
Authors \\ Svein Arne Pettersen ${ }^{1}$, Tormod Brenn ${ }^{2}$
}

\author{
Affiliations \\ 1 Faculty of Health Sciences, School of Sport Sciences UiT - \\ The Arctic University of Norway, Tromsø, Norway \\ 2 Department of Community Medicine, Faculty of Health \\ Sciences, UiT - The Arctic University of Norway, Tromsø, \\ Norway
}

Key words
tracking, external load, playing position, high-intensity
profile, maximum speed

$\begin{array}{ll}\text { received } & 17.12 .2018 \\ \text { revised } & 28.02 .2019 \\ \text { accepted } & 16.03 .2019\end{array}$

\section{Bibliography}

DOI https://doi.org/10.1055/a-0883-5540

Sports Medicine International Open 2019; 3: E19-E24

(C) Georg Thieme Verlag KG Stuttgart · New York

ISSN 2367-1890

\section{Correspondence}

Svein Arne Pettersen

School of Sport Sciences,

University of Tromsoe, the Arctic University,

9037 Tromsoe,

Norway

Tel : +4793229644, Fax : +4777688118

svein.arne.pettersen@uit.no

\begin{abstract}
In order to investigate activity profiles and external load patterns in elite youth soccer players, we studied high-intensity activity patterns, maximum running speed, and temporary and end-of-match decline in external load in 54 U17 players (96 match observations) over a full season of official match play. Wide midfielders covered most high-intensity running (HIR) distance (1044.2 m), most sprinting distance (224.4 m), and the highest number of accelerations (185.2); center defenders had the lowest values for these activities $(508.3 \mathrm{~m}, 85.1 \mathrm{~m}$, and $119.0)$, respectively. Wide midfielders had the highest and center defenders had the lowest maximum speed $\left(30.3 \mathrm{~km} \cdot \mathrm{h}^{-1}\right.$ and $\left.28.6 \mathrm{~km} \cdot \mathrm{h}^{-1}\right)$, respectively. During the matches, players in all playing positions displayed a significant drop in HIR distance, sprinting distance, and number of accelerations. This was especially pronounced in the 5 min following the 5 -min peak period and in the last 5 -min period for sprinting distance.

There are substantial differences in activity profiles by positions, but all players show temporary and end-of-match drop in external load. The variation in activity profiles by playing position in this study may aid in the design of training programs. The considerable end-of-match drop in external load observed raises the question of the favorability of 90 min match times for U17 players.
\end{abstract}

\section{Introduction}

Results from time-motion studies are useful for assessing the physiological demands of training and match play in soccer. They allow quantification of player running activities and indirect verification of the energetics of match play [10]. Despite the use of various tracking systems, there is a general consensus that adult players cover a distance of 10-12 km per match [28]. A study of English Premier League players showed that the mean distance covered during a 90 -min match was $10714 \mathrm{~m}$, of which $936 \mathrm{~m}$ were highintensity running (HIR) $\left(19.8-25.1 \mathrm{~km} \cdot \mathrm{h}^{-1}\right)$ and $251 \mathrm{~m}$ were sprinting $\left(>25.1 \mathrm{~km} \cdot \mathrm{h}^{-1}\right)$ [7]. HIR and sprint-type activities are consid- ered to be crucial determinants for successful performance and discriminate high- and low-level adult players [21]. Recently, HIR $\left(19.8-25.2 \mathrm{~km} \cdot \mathrm{h}^{-1}\right)$ distance and sprinting $\left(>25.2 \mathrm{~km} \cdot \mathrm{h}^{-1}\right)$ distance were measured at $668 \mathrm{~m}$ and $143 \mathrm{~m}$, respectively, in a Danish Superliga club, with no significant differences between U17 and adult players [31].

Although there are limited data on match play in youth elite players, the data that do exist show that the total distance covered during match play increases with age to approximately $10 \mathrm{~km}$ in 18 -year-old players $[8,16,20,25,27]$. When adjusted for match time, differences still exist but are less apparent, especially at older 
ages [8]. On the other hand, total distance is only slightly greater in top-class players compared to moderate-class players, indicating that total distance does not distinguish between players at various levels [21]. Less is known about distance covered at various speeds by youth elite soccer players during match play. One report showed that U16 players covered more distance at all speeds than U12-U15 players [16], and when adjusted for match time, U18 players covered more sprinting $\left(>19.1 \mathrm{~km} \cdot \mathrm{h}^{-1}\right)$ distance than U13U17 players [9].

In accordance with adult elite soccer players $[5,6,13]$ running performance is influenced by playing position in elite youth players. In 263 male elite soccer players aged 8-18 years from three professional academies, center backs covered the shortest and wide midfielders the longest HIR and sprinting distances [27]. In 52 international cup matches (380 players, mean age 16.0 years), center defenders covered the shortest very high-speed $\left(\geq 19.8 \mathrm{~km} \cdot \mathrm{h}^{-1}\right)$ and sprint ( $\geq 25.2 \mathrm{~km} \cdot \mathrm{h}^{-1}$ ) distances, whereas wide players and center forwards covered the longest distances in these speed zones [30], which is in line with other studies [9, 20].

In adult elite soccer players, acceleration profiles differ by playing position, but we found no studies on the U17 population. Running and acceleration profiles could be important to successfully tailor position-specific physical training programs that mimic and surpass the physiological demands of a match, and they may also play a role in the development of relevant physiological tests [11].

Few studies have addressed temporary and end-of-match drop in external load in youth elite players. In two friendly games with players aged 17.6 years on average, significantly lower activity was found for HIR ( $\left.\geq 19.8 \mathrm{~km} \cdot \mathrm{h}^{-1}\right)$, sprinting $\left(\geq 25.2 \mathrm{~km} \cdot \mathrm{h}^{-1}\right)$, and acceleration $\left(2 \mathrm{~m} \cdot \mathrm{s}^{-2}\right)$ after the 5 -min peak period. However, only acceleration was significantly lower in the last 5 min of the match [25]. Understanding the peaks and drops in external load could help coaches in prescribing position-specific training load.

There are scarce data examining the peak running speed in elite youth soccer players despite the substantial practical applications such data may have on training prescription. In English Premier League academy players with a mean age of 19.9 years, the highest mean maximum speed was $31.0 \mathrm{~km} \cdot \mathrm{h}^{-1}$, which was observed among wide attackers [1]. Al Haddad, Simpson, Buchheit, et al. [3] observed a peak match speed of $26.8 \mathrm{~km} \cdot \mathrm{h}^{-1}$ in 60 elite U17 players, and when merging U13-U17 players in one pool, center forwards $\left(\mathrm{n}=52\right.$ ) were the fastest position at $27.0 \mathrm{~km} \cdot \mathrm{h}^{-1}$. During the last several decades, soccer players have become faster, and youth soccer players with high maximum speed may be identified as potential professional players $[18,22]$. Thus there is a need for results on the maximum speed required in different positions in elite youth players.

To our knowledge, there is no study reporting activity profiles and external load patterns by playing position and match time period in youth elite soccer players on both home and away teams. In order to investigate these aspects, we studied high-intensity activity patterns, maximum running speed, and temporary and end-of-match external load in U17 players over a full season of official match play.

\section{Materials and Methods}

The study comprised data from 54 players collected during eight matches played on a single playing field $(110 \times 68 \mathrm{~m}$ outdoor arti- ficial grass field) during the full 2016 season (6 months) of official match play. Included players came from six teams: five of the highest-ranked U17 teams in the Norwegian National League (1 home and 4 away teams) and one of the cup finalist clubs (U17 National Cup, away team). Players were categorized into the following playing positions: center defenders, wide defenders, center midfielders, wide midfielders, or center forwards. Only players who completed a full match $(90 \mathrm{~min})$ in the same playing position were included in the analysis. Some players in the sample were used in different playing positions across matches. Altogether, 14 players from the home team played between one and eight matches, generating 58 match observations. 38 players from the five away teams were also tracked during these same matches, generating 38 match observations. Thus the total number of match observations was 96. This study conformed to the IJSM ` s ethical standards document [17], was approved by the Norwegian Data Inspectorate, and received institutional approval from UiT The Arctic University of Norway Institutional Review Board.

\section{Data collection}

A stationary radio-based tracking system (ZXY Sport Tracking System, ZXY Sport Tracking AS, Trondheim, Norway, http://chyronhego.com/sports-data/zxy) (Bendiksen et al., 2013) was used to monitor players' activity. Each player wore a specially designed belt wrapped tightly around the waist with a small sensor located at the lumbar spine, and data were transferred by microwave radio channel to 6 RadioEye ${ }^{T M}$ sensors (ZXY Sport Tracking AS). The ZXY Sport Tracking System provides information regarding distance traveled in different speed zones and the number of accelerations, both positive and negative.

Distance covered was measured as HIR for speeds between 19.8 and $25.2 \mathrm{~km} \cdot \mathrm{h}^{-1}$, and as sprinting for speeds of $25.2 \mathrm{~km} \cdot \mathrm{h}^{-1}$ or more. Accelerations were defined by 4 event markers: 1$)$ the player reached a minimum of $\left(1 \mathrm{~m} \cdot \mathrm{s}^{-2}\right)$ to mark the start of the acceleration, 2) the player reached and exceeded the acceleration limit $\left.\left(2 \mathrm{~m} \cdot \mathrm{s}^{-2}\right), 3\right)$ the player remained above this limit for at least half a second, and 4) the acceleration event ended when the player fell below the minimum acceleration speed. Maximum speed was measured as the highest speed, offensive or defensive, reached during the match. The accuracy and reliability of the ZXY Sport Tracking System in measuring player movements in match-play have been described in previous studies [19,24]).

To assess temporary and end-of-match external load, activity profiles were generated by match period for each playing position, separating matches into six 15 -min periods and into 18 non-overlapping 5 -min periods. Within the 5 -min periods, we identified the most intense (peak) 5-min period, the 5 min following the peak 5 -min period, the average of all 5-min periods, and the last 5-min period.

\section{Statistical analysis}

Data were analyzed as total match activity profiles in order to describe playing position-specific game demands by using a one-way ANOVA with Bonferroni as the multiple comparison procedure. When testing each player's change in performance over time, a repeatedmeasures ANOVA with possible adjustments according to Mauchly's test of sphericity was used. Thereby each playing position and time effects, including their interactions, were assessed." Contrasts were 
used to test the last 15-min period versus the mean of the other five 15 -min periods, and to test the peak 5 -min period versus the 5 min following the peak 5 -min period, the 5 min following the peak 5 -min period versus the average of all 5 -min periods, and the average of all 5 -min periods versus the last 5 -min period. All analyses were performed using SAS 9.4 (SAS Institute, Cary, NC, USA).

\section{Results}

There were significant differences between playing positions for total running distance, HIR distance, and sprinting distance. The main pattern was that center defenders were less active than players at other playing positions. This was especially pronounced for HIR distance (508.3 $\mathrm{m}$ for center defenders versus $748.8 \mathrm{~m}$ for wide defenders, who were the second least active) and sprinting distance (85.1 $\mathrm{m}$ for center defenders, versus $105.4 \mathrm{~m}$ for center midfielders, who were second least active). Wide midfielders had the longest HIR distance (1044.2 m), followed by center forwards ( $854.8 \mathrm{~m}$ ); and wide midfielders also had the longest sprinting distance $(224.4 \mathrm{~m})$, again followed by center forwards (143.3 m). The standard deviation within each playing position was considerable, illustrating a large difference in activity among players in the same playing position ( $\triangleright$ Table $\mathbf{1}$ ).

With respect to external load, dividing the 90 -min matches into 15-min periods showed a time effect with significantly less activity observed during the last $15 \mathrm{~min}$ in all playing positions. This trend was most pronounced for wide midfielders, who were the most active players ( $>$ Fig. 1). A large difference in activity was also displayed when 5-min periods were investigated, with the peak 5-min period having much higher values than all other 5 -min periods. The 5 min following the peak 5 -min period were somewhat less active than the average of all 5-min periods. Finally, the last 5-min period was less active than the average of all 5-min periods. In terms of percentages, reductions in the last 5 -min period relative to the average value of the rest of the 5-min periods were 7.8, 18.0, 48.0, and 22.0 for total distance, HIR distance, sprinting distance, and number of accelerations, respectively. This pattern was fairly similar across all playing positions ( $\mathbf{F i g .} \mathbf{2}$ ).

Wide midfielders had the highest maximum speed (mean maximum speed $30.3 \mathrm{~km} \cdot \mathrm{h}^{-1}$ ). The player with the highest maximum speed was also a wide midfielder, who reached a maximum speed of $32.8 \mathrm{~km} \cdot \mathrm{h}^{-1}$. The player with the lowest maximum speed was a center defender $\left(24.8 \mathrm{~km} \cdot \mathrm{h}^{-1}\right)$ ( Table 2$)$.

\section{Discussion}

This study shows that U17 players have difficulty maintaining the same standard of running and acceleration performance throughout the course of a match. This trend was especially pronounced for sprinting distance. A temporary drop in external load was also demonstrated after the peak 5-min period. Indeed, in the 5 min following the peak 5 -min period, players at all playing positions showed a significant drop in all high-intensity activities. Another study found a similar temporary drop in U19 players, but showed that only accelerations dropped the last 5-min period [25]. A more mature pacing strategy and/or superior training status may explain this difference, because the contextual situation with no team controlling the latter stages of the matches was equal. Similarly, tracking 380 U17 players in an international tournament revealed that running performance was reduced in the second half of the match compared with the first half [30].

The distinct activity profiles we observed by playing position are similar to those seen in other studies of youth elite soccer players $[1,8,31]$ and adult professional soccer players [7]. This also applies to wide midfielders and center forwards covering the most distance at high speeds $[4,8,20]$. On the other hand, one study including elite youth soccer players found a somewhat different pattern, with center defenders covering the least HIR and sprinting distances, and wide defenders covering more sprinting distance than wide midfielders [30]. The rather low HIR and sprinting distances observed among wide defenders in the present study may be affected by the wide midfielders being very active and forcing the wide defenders not to leave too much space available while attacking.

Center midfielders cover the most total distance, because this playing position links offence and defense and thus requires continuous movement $[20,30,31]$. Our wide midfielders covered by far the longest HIR and sprinting distances, which may be related to the task these players have to penetrate the opposition's defense. Center forwards covered the second most HIR and sprinting distances, indicating that this ability is important to create scoring opportunities [14].

Pacing strategy and/or tactical considerations may have also partly affected the results. In addition, we must be careful when making direct comparisons of absolute values, even if the exact same cut-offs are used, owing to the substantial differences between tracking systems [26].

- Figs. 1 and $\mathbf{2}$ show a high-intensity activity profile, in which wide midfielders had superior performance compared to other

- Table 1 Overall activity profiles by playing position as mean values \pm s for U17 elite soccer players.

\begin{tabular}{|c|c|c|c|c|c|}
\hline Playing position & $\begin{array}{l}\text { Number of player- } \\
\text { match observations }\end{array}$ & Total distance (m) & $\begin{array}{l}\text { High-intensity } \\
\text { running distance (m) }\end{array}$ & $\begin{array}{l}\text { Sprinting } \\
\text { distance }(\mathrm{m})\end{array}$ & $\begin{array}{l}\text { Number of } \\
\text { accelerations (n) }\end{array}$ \\
\hline Center defenders & 23 & $10396.8 \pm 534.4^{b}$ & $508.3 \pm 182.0^{c}$ & $85.1 \pm 61.4$ & $119.0 \pm 17.8^{f}$ \\
\hline Wide defenders & 22 & $11366.9 \pm 679.1$ & $748.8 \pm 269.1$ & $116.5 \pm 78.0$ & $143.1 \pm 42.0^{9}$ \\
\hline Center midfielders & 27 & $11989.4 \pm 939.4$ & $782.9 \pm 297.0$ & $105.4 \pm 101.2$ & $155.6 \pm 36.1$ \\
\hline Wide midfielders & 12 & $11546.3 \pm 838.5$ & $1044.2 \pm 168.2^{d}$ & $224.4 \pm 82.4^{\mathrm{e}}$ & $185.2 \pm 30.1$ \\
\hline Center forwards & 12 & $11508.5 \pm 831.4$ & $854.8 \pm 146.0$ & $143.3 \pm 71.9$ & $167.9 \pm 16.5$ \\
\hline $\mathrm{p}$-value ${ }^{\mathrm{a}}$ & - & $<0.0001$ & $<0.0001$ & $<0.0001$ & $<0.0001$ \\
\hline \multicolumn{6}{|c|}{$\begin{array}{l}\text { a } p \text {-value for test of equal means; }{ }^{b} p<0.05 \text { vs. each of the other four positions; }{ }^{c} p<0.05 \text { vs. each of the other four positions; }{ }^{d} p<0.05 \text { vs. wide } \\
\text { defenders and center midfielders; }{ }^{e} p<0.05 \text { vs. center defenders, wide defenders and center midfielders; }{ }^{f} p<0.05 \text { vs. center midfielders, wide } \\
\text { midfielders and center forwards; }{ }^{9} p<0.05 \text { vs. wide midfielders. }\end{array}$} \\
\hline
\end{tabular}



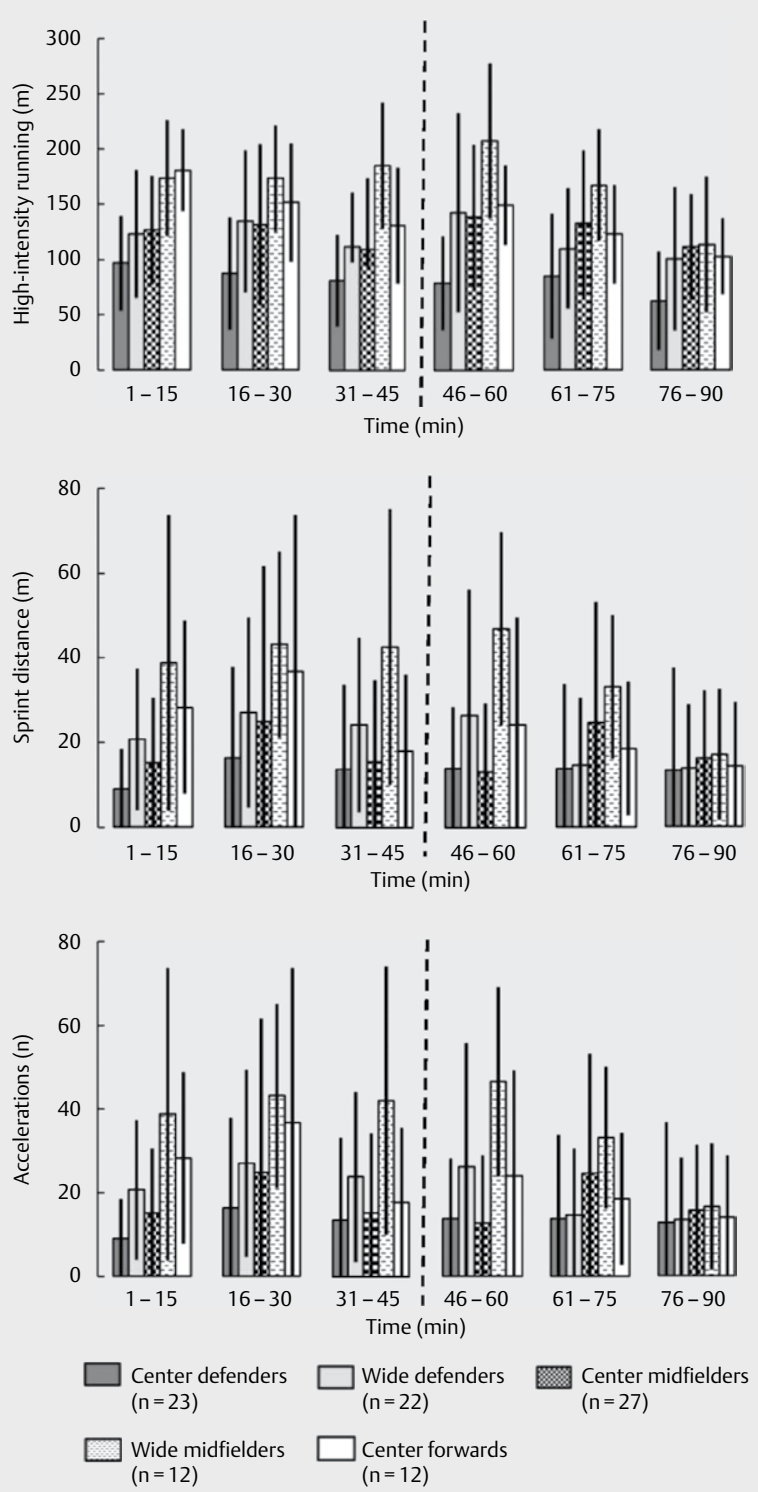

- Fig. 1 Performance data in 15-min intervals by playing position. Data are presented as means with standard deviations as error bars. For position: $p<0.0001$ for all three performances. For time: $p<0.0001$ for high-intensity running and acceleration and $p=0.0002$ for sprint. For position time interaction: $p>0.05$ for all performances. For period 76-90 min: $p<0.0001$ vs. the mean of the 5 other time periods.

playing positions but also the most pronounced drop in external load in the last 5-min period. In addition to covering the longest HIR and sprinting distances and having the largest number of accelerations, wide midfielders also displayed the highest maximum speed of $30.3 \mathrm{~km} \cdot \mathrm{h}^{-1}$. In sum, the physical load on these players seems to be greater than that of other playing positions, and this may explain the larger drop in performance the last 5-min period. It has been argued that center midfielders have less space to perform high-speed actions but perform more accelerations than other playing positions [29]. This is not supported by our study, in which both wide midfielders and center forwards had more accel-
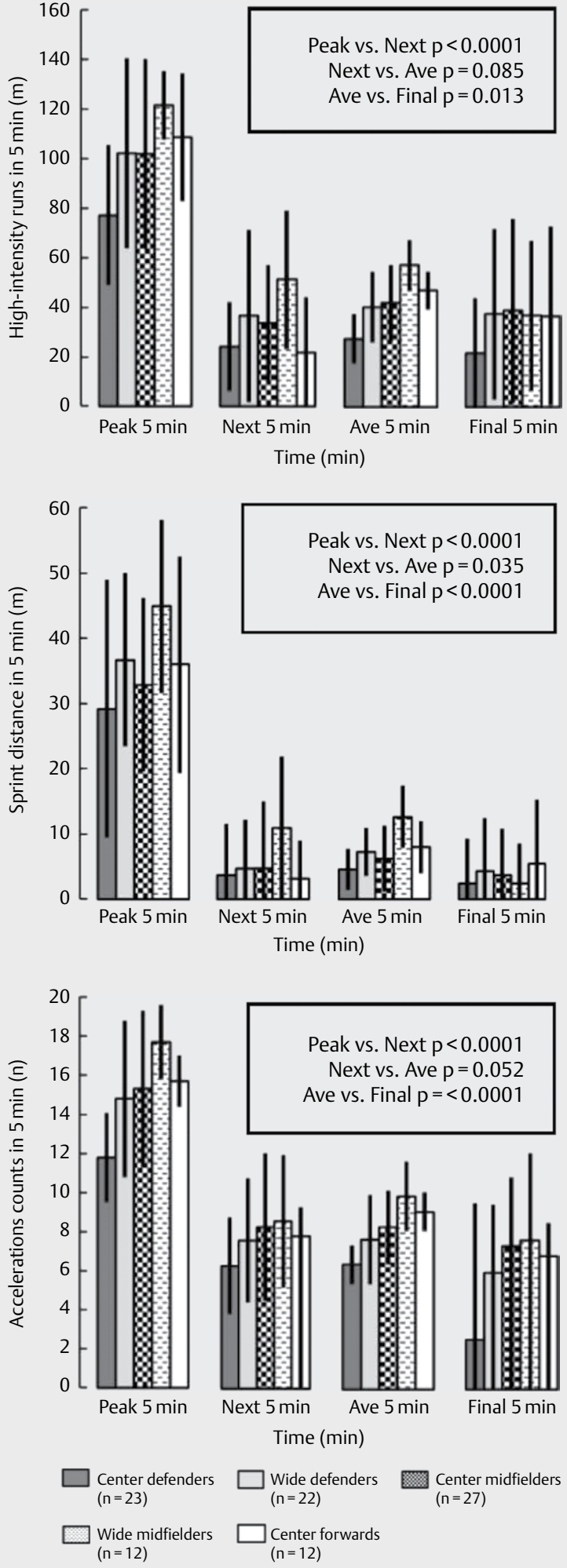

-Fig. 2 Performance data in the peak 5 -min period during the game, the $5 \mathrm{~min}$ following the peak, the average $5 \mathrm{~min}$ and the final 5 min of the game. Data are presented as means with standard deviations as error bars. For positions: $p=0.0007$ for high-intensity runs, $p=0.053$ for sprint and $p<0.0001$ for acceleration. For position time interaction: $p>0.05$ for all performances. For Peak vs. Next, Next vs. Ave and Ave vs. Final, see figure. 
- Table 2 Maximum speed by playing position for U17 elite soccer players.

\begin{tabular}{|c|c|c|c|c|}
\hline Player position & $\begin{array}{l}\text { Number of player- } \\
\text { match observations }\end{array}$ & $\begin{array}{l}\text { Maximum speed, } \\
\mathrm{km} \cdot \mathrm{h}^{-1} \mathrm{a}, \mathrm{b}\end{array}$ & $\begin{array}{l}\text { Lowest maximum } \\
\text { speed, } \mathbf{k m} \cdot \mathrm{h}^{-1}\end{array}$ & $\begin{array}{l}\text { Highest maximum } \\
\text { speed, } \mathrm{km} \cdot \mathrm{h}^{-1}\end{array}$ \\
\hline Center defenders & 23 & $29.0 \pm 1.9$ & 24.8 & 31.7 \\
\hline Wide defenders & 22 & $29.6 \pm 1.0$ & 27.9 & 31.1 \\
\hline Center midfielders & 27 & $28.6 \pm 1.5$ & 25.2 & 31.8 \\
\hline Wide midfielders & 12 & $30.3 \pm 1.5$ & 27.0 & 32.8 \\
\hline Center forwards & 12 & $29.2 \pm 1.9$ & 25.5 & 31.9 \\
\hline
\end{tabular}

erations than center midfielders. Wide midfielders were also the player position most often substituted, perhaps because of the drop in end-of-match external load; thus we had only 12 match observations for this group.

Our study confirmed that coaches tend to prefer fast players as wide midfielders in Norwegian youth elite soccer, because wide midfielders had the fastest maximum speed ( $\bullet$ Table 2 ). Wide center forwards had the fastest mean maximum speed among English Premier League academy players (mean age 19.9 years) and only this position had a greater maximum speed than the U17 players in the present study [1]. In contrast, center forwards $(n=52)$ had the highest maximum speed $\left(27.0 \mathrm{~km} \cdot \mathrm{h}^{-1}\right)$ in a study of elite U13U17players [3], but we must take into consideration the use of different tracking methodologies.

Recent studies have shown that acceleration, both positive and negative, can require high effort without any high-speed actions $[15,23,31]$. During a match, elite adult and youth players showed a more pronounced decline in accelerations than in HIR and sprinting distances, indicating that accelerations may be a more sensitive measure of drop in external load [2, 25]. The present study showed a significant decline not only in accelerations but also in HIR and sprinting distances the last 5 min of the matches.

As a drop in external load is clearly demonstrated toward the end of matches, one may consider a redisposition of center defenders. Indeed, they move less than other players during the match and thereby could have some extra energy and produce more attacking power. Non-fatigued center defenders could be sent to forward attacking positions, while using other fatigued players as cover. However, our data indicate that center defenders had a drop in external load similar to other players during the last 5 min of matches. This is supported by significantly fewer accelerations in center defenders compared to wide midfielders, center midfielders, and center forwards. In contrast, player load (effort) per m has been found to be significantly higher in center defenders than in other playing positions, as measured by ZXY-Sport Tracking [12]. The algorithm calculating player load has not been validated and may overestimate the effort required for jumping, sliding, and backward running, because goalkeepers using ZXY Sport Tracking accumulate a very high player load per $m$ traveled. This may be due to shaking of the transponder during jumps and dives, aggregating a high player load (personal observations).

\section{Limitations}

There are several limitations to this study. ZXY Sport Tracking uses uniform speed thresholds that cannot be individualized depending on the varying maximum speed of different players. On the other hand, using thresholds identical to other studies of both youth and adult elite soccer players allows for the comparison of results $[30,31]$. The metabolic cost of accelerations varies, because creating an acceleration when traveling at $18 \mathrm{~km} \cdot \mathrm{h}^{-1}$ is much more demanding than creating one when traveling at $4 \mathrm{~km} \cdot \mathrm{h}^{-1}$. Because most observations in the present study are from home-team players, contextual skewness of the results may have appeared [29]. All matches were either tied, or one team led by one goal up until the final minutes, indicating that any effect of controlling the match at the latter stage should be minor. But interpreting the drop in external load at the end of the game or temporarily after the most intense period is highly complex, because it could be attributed to physical or mental fatigue, pacing strategies, contextual factors, or a combination of these factors.

\section{Practical considerations}

Match length for U17 players in Norway is set at the same time as for adult players, i. e., two 45 -min periods. The degree of drop in external load demonstrated in this study raises the question whether such young players are able to cope with matches of such long duration. Considering the physical demands required for different playing positions during match play, training emphases should differ. To overload players during training, it might be better to focus on peak playing position intensities rather than mean values, so that players are prepared for the most demanding periods of matches.

\section{Conflict of Interest}

Authors declare that they have no conflict of interest.

\section{References}

[1] Abbott W, Brickley G, Smeeton NJ. Physical demands of playing position within English Premier League academy soccer. JHSE 2018; 13: 11

[2] Akenhead R, Hayes PR, Thompson KG, French D. Diminutions of acceleration and deceleration output during professional football match play. J Sci Med Sport 2013; 16: 556-561

[3] Al Haddad H, Simpson BM, Buchheit M, Di Salvo V, Mendez-Villanueva A. Peak match speed and maximal sprinting speed in young soccer players: Effect of age and playing position. Int J Sports Physiol Perform 2015; 10: 888-896 
[4] Aslan A, Acikada C, Guvenc A, Goren H, Hazir T, Ozkara A. Metabolic demands of match performance in young soccer players. J Sports Sci Med 2012; 11: 170-179

[5] Baptista I, Johansen D, Seabra A, Pettersen SA. Position specific player load during match-play in a professional football club. PLoS One 2018; 13: e0198115

[6] Bradley PS, Di Mascio M, Peart D, Olsen P, Sheldon B. High-intensity activity profiles of elite soccer players at different performance levels. J Strength Cond Res 2010; 24: 2343-2351

[7] Bradley PS, Sheldon W, Wooster B, Olsen P, Boanas P, Krustrup P. High-intensity running in English FA Premier League soccer matches. J Sports Sci 2009; 27: 159-168

[8] Buchheit M, Mendez-Villanueva A, Simpson BM, Bourdon PC. Match running performance and fitness in youth soccer. Int J Sports Med 2010; 31: 818-825

[9] Buchheit M, Mendez-villanueva A, Simpson BM, Bourdon PC. Repeated-sprint sequences during youth soccer matches. Int J Sports Med 2010; 31: 709-716

[10] Carling C. Interpreting physical performance in professional soccer match-play: Should we be more pragmatic in our approach? Sports Med 2013; 43: 655-663

[11] Carling C, Bloomfield J, Nelsen L, Reilly T. The role of motion analysis in elite soccer: Contemporary performance measurement techniques and work rate data. Sports Med 2008; 38: 839-862

[12] Dalen T, Ingebrigtsen J, Ettema G, Hjelde GH, Wisloff U. Player load, acceleration, and deceleration during forty-five competitive matches of elite soccer. J Strength Cond Res 2016; 30: 351-359

[13] Di Salvo V, Baron R, Tschan H, Calderon Montero FJ, Bachl N, Pigozzi F. Performance characteristics according to playing position in elite soccer. Int J Sports Med 2007; 28: 222-227

[14] Faude $O$, Koch T, Meyer T. Straight sprinting is the most frequent action in goal situations in professional football. J Sports Sci 2012; 30: 625-631

[15] Gaudino P, laia FM, Alberti G, Strudwick AJ, Atkinson G, Gregson W. Monitoring training in elite soccer players: Systematic bias between running speed and metabolic power data. Int J Sports Med 2013; 34 : 963-968

[16] Harley JA, Barnes CA, Portas M, Lovell R, Barrett S, Paul D, Weston M. Motion analysis of match-play in elite U12-U16 age-group soccer players. J Sports Sci 2010; 28: 1391-1397

[17] Harriss DJ, Macsween A, Atkinson G. Standards for ethics in sport and exercise science research: 2018 update. Int J Sports Med 2017; 38: $1126-1131$
[18] Haugen T, Tonnessen E, Hisdal ], Seiler S. The role and development of sprinting speed in soccer. Int J Sports Physiol Perform 2014; 9: 432-441

[19] Ingebrigtsen J, Dalen T, Hjelde GH, Drust B, Wisloff U. Acceleration and sprint profiles of a professional elite football team in match play. Eur J Sport Sci 2015; 15: 101-110

[20] Mendez-Villanueva A, Buchheit M, Simpson B, Bourdon PC. Match play intensity distribution in youth soccer. Int J Sports Med 2013; 34: 101-110

[21] Mohr M, Krustrup P, Bangsbo J. Match performance of high-standard soccer players with special reference to development of fatigue. J Sports Sci 2003; 21: 519-528

[22] Murtagh CF, Brownlee TE, O'Boyle A, Morgans R, Drust B, Erskine RM. Importance of speed and power in elite youth soccer depends on maturation status. J Strength Cond Res 2018; 32: 297-303

[23] Osgnach C, Poser S, Bernardini R, Rinaldo R, di Prampero PE. Energy cost and metabolic power in elite soccer: A new match analysis approach. Med Sci Sports Exerc 2010; 42: 170-178

[24] Pettersen SA, Johansen HD, Baptista IAM, Halvorsen P, Johansen D. Quantified soccer using positional data: A case study. Front Physiol 2018; 9: 866

[25] Pettersen SA, Krustrup P, Bendiksen M, Randers MB, Brito ], Bangsbo ], jin Y, Mohr M. Caffeine supplementation does not affect match activities and fatigue resistance during match play in young football players. J Sports Sci 2014; doi:10.1080/02640414.2014.965189: 1-8

[26] Randers MB, Mujika I, Hewitt A, Santisteban ], Bischoff R, Solano R, Zubillaga A, Peltola E, Krustrup P, Mohr M. Application of four different football match analysis systems: A comparative study. J Sports Sci 2010; 28: 171-182

[27] Saward C, Morris JG, Nevill ME, Nevill AM, Sunderland C. Longitudinal development of match-running performance in elite male youth soccer players. Scand J Med Sci Sports 2016; 26: 933-942

[28] Stolen T, Chamari K, Castagna C, Wisloff U. Physiology of soccer: An update. Sports Med 2005; 35: 501-536

[29] Varley MC, Aughey RJ. Acceleration profiles in elite Australian soccer. Int J Sports Med 2013; 34: 34-39

[30] Varley MC, Gregson W, McMillan K, Bonanno D, Stafford K, Modonutti M, Di Salvo V. Physical and technical performance of elite youth soccer players during international tournaments: influence of playing position and team success and opponent quality. J Sci Med Football 2016; 1: 18-29

[31] Vigh-Larsen JF, Dalgas U, Andersen TB. Position-specific acceleration and deceleration profiles in elite youth and senior soccer players. J Strength Cond Res 2018; 32: 1114-1122

\section{Notice}

This article was changed according to the erratum on July 17, 2019.

\section{Erratum}

In the above-mentioned article, one sentence in the abstract was published wrong. Correct is:

Wide midfielders covered most high-intensity running (HIR) distance (1044.2 m), most sprinting distance (224.4 m), and the highest number of accelerations (185.2); center defenders had the lowest values for these activities (508.3 m, $85.1 \mathrm{~m}$, and 119.0), respectively. 